（昭和 35 年 11 月造船協会秋季講演会に拈いて講演）

\title{
矩形水槽壁の接水振動について(第3 報)
}

\section{正員 鬼 頭 史 城*}

On Vibration of a Rectangular Tank Filled with Water III.

By Fumiki Kito, Member.

Summary

When side walls of a rectangular tank, which is filled with water, is vibrating, the inside water will also make vibratory motion. This motion of water lowers considerably the natural frequency of vibration of the side walls of the tank. This effect is conveniently expressed by "Virtual Mass" of water. In the previous report, the author has made a theoretical study on the value of "virtual mass" of water, restricting ourselves to the case in which two opposite side-walls (among the six walls) are vibrating. The present report is an outcome of continuation of this study, and treats the case in which four walls of the tank vibrate. An approximate formulae for natural frequency of vibration for whole system consisting of four walls and the inside water, is also given.

The calculation throughout is made, regarding the water to be an incompressible, non-viscous fluid, and the amplitude of vibration to be infinitesimally small.

\section{1. 緒言}

矩形水槽があつて，その内部に水がみたされているとする。その側壁を構成するところの矩形平板が振動する とき, 内部の水もまた振動をする。その結果, 平板の固有振動に対して, いわゆる仮性質量の効果が現われる。 著者は前 2 回の報告(1)(2) に掞いて，相向つている 2 枚の側壁が振動するときの水の仮性質量の值について理論 的考察を行ない，その值を与えるところの略近公式を作つた。矩形壁のうちで，相向つている 2 面だけが振動し ている場合をとり上げたのは，実際上とのようなケースがしばしば起つたからである。しかし，一般理論として は, 同時に（例えば） 4 面の矩形壁面の振動する場合をも考える必要がある。本報告では 4 つの側面（弾性矩形 平板）と内部の水とで構成された 1 つ振動系を考え, 水の上面には自由面があり, 板は反相振動をする場合に 対して前回と同様な水の動エネルギーの計算を行ない，かつ Lord Rayleigh の原則を応用して，固有振動数に 対する略近公式を作つた。そして数值例によつてその適用法を説明してある。

水は非生縮性理想流体と考光，かつ微小振動の場合だけを考兄ている。また前回報告と同じく下記の記号を用 いる。

$\phi=$ 水の運動の速度ポテンシャル, $w=$ 平板の横変位, $A=$ 同上の振幅, $\rho=$ 振動の角周波数, $L=$ 矩形水槽の長 さ, $H=$ 同上の高さ, $B=$ 同上の幅, $N=$ 斜辺の長さ $=\sqrt{L^{2}+H^{2}}, \rho_{m}=$ 平板の材質の密度, $\rho_{w}=$ 水の密度, $W=$ $\omega A$ (板の横変位速度の振幅值), $T_{m}$ 二板の動エネルギー, $T_{w}$ 二水の動エネルギー, $V=L B H=$ 矩形水槽の容 積, $m=\pi / L, s=\pi / H, M=\pi / B, n_{i j}=\left[(m i)^{2}+(s j)^{2}\right]^{1 / 2}, N_{i j}=\left[(M i)^{2}\right.$ $\left.+(s j)^{2}\right]^{1 / 2}$,

第 1 図に示すごとく，水槽の壁面のうち $L \times H$ の寸法をもつた 2 面を側面， $B \times H$ の寸法をもつた 2 面を端面と，仮りに名付けよう。 今回は両側面と両端面とが同時に振動する場合を考えるのであつて, 側面に関する量に $a$, 端面に関する量に $b$ なるサフィクスを付けて区 別することにする。 $w_{a}, W_{a}$ は側面板の振動的変位に, $w_{b}, W_{b}$ は端面 板の振動的変位に，それぞれ関係のある量となる。 $\phi_{a}$ は $w_{a}$ が存在 し, $w_{b} \equiv 0$ のときの水槽内部の水の運動の速度ポテンシャルをそれ

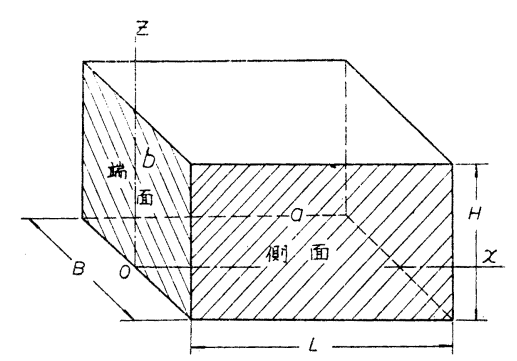

第 1 図 矩形水槽の略図

* 慶応義塾大学工学部 
ぞれ表わすものとする。

\section{2. 水の動エネルギーの計算（ 2 枚の側面板と 2 枚の端面板が同時に振動する場合） （反相振動）(自由表面あり)}

計算の目標を最低自由振動数の計算におくものとする。前回までの研究によると向合つた 2 面が反相振動をす る場合の方が仮性質量の值が大きく，したがつて自由振動数の值を低くする。それゆ克，ここでは両側面板が， また両端面板が，いずれも反相振動をする場合を考光よう。な和水はほとんぞ完全にみたされているが，上面に 僅かの空間を残して扣り，したがつて上面は自由面であるとしよう。

2 枚の側面板が

$$
\frac{d w_{a}}{d t}=W_{a} \sin m x \sin s z \cos \omega t
$$

の形で（反相）振動しているとき，水の運動の速度ポテンシャル $\phi_{a}$ の值は1)

$$
\phi_{a}=\sum \sum B_{i j} \cosh \left(n_{i j} y\right) \cos (m i x) \cos (s j z)
$$

の形になる。ここに

$$
B_{i j}=\frac{2}{\left(i^{2}-1\right)\left(j^{2}-1\right)}\left(\frac{\varepsilon}{\pi^{2}}\right) \frac{W_{a} \cos \omega t}{n_{i j} \sinh \left(n_{i j} B / 2\right)}
$$

であり，総和記号 $\sum \sum$ は $i=0,2,4, \cdots ; j=\sigma+\frac{1}{2}, \sigma=01,2, \cdots$ に対する総和を示すものとする。 $\varepsilon$ は $i=0$ の とき $\varepsilon=2, i \neq 0$ のとさ $\varepsilon=4$ となるものとする。

2 枚の端面板が変位速度

$$
\frac{d w_{b}}{d t}=W_{b} \cos M y \sin s z \cos \omega t
$$

(ただし $-B / 2 \leqq y \leqq+B / 2)$ で振動しているときに対する水の運動の速度ポテンシャル $\phi_{b}$ の值は， $\phi_{a}$ から， 記号の括きかえを行なつて得られる。すなわち

$$
\phi_{b}=\sum \Sigma C_{i j} \cosh \left\{N_{i j}\left(x-\frac{L}{2}\right)\right\} \cos \left\{M i\left(y+\frac{B}{2}\right)\right\} \cos s j z
$$

ここに

$$
C_{i j}=\frac{2}{\left(i^{2}-1\right)\left(j^{2}-1\right)}\left(\frac{\varepsilon}{\pi^{2}}\right) \frac{W_{b} \cos \omega t}{N_{i j} \sinh \left(N_{i j} L / 2\right)}
$$

であり, 総和記号 $\sum \sum$ および $ょ$ の值のとり方は $\phi_{a}$ の場合と同じである。両側面と, 両端面と, 4 枚の矩形板 が同時に振動しているときの, 水の運動の速度ポテンシャルは $\phi=\phi_{a}+\phi_{b}$ によつて与兄られる。この場合に, 水域全体の水の動エネルギー $T_{w}$ の值は

$$
T_{w}=\frac{\rho_{w}}{2} \iint \phi \frac{\partial \phi}{\partial n} d S
$$

を全境界面にわたつて面積分することによつて得られる。ところが上面は自由面であり，かつ略近的に $\phi=0$ と してあるし，また底面は固定されて動かないものとしてあるから，両側面拈よび両端面の 4 面に対して積分を行 な党ばよい。よつて

の形になる。ここで

$$
T_{w}=T_{a a}+T_{a b}+T_{b a}+T_{b b}
$$

$$
\begin{aligned}
& T_{a a}=\frac{\rho_{w}}{2} \iint \phi_{a} \frac{\partial \phi_{a}}{\partial n} d S, \quad T_{b a}=\frac{\rho_{w}}{2} \iint \phi_{a} \frac{\partial \phi_{b}}{\partial n} d S, \\
& T_{a b}=\frac{\rho_{w}}{2} \iint \phi_{b} \frac{\partial \phi_{a}}{\partial n} d S, T_{b b}=-\frac{\rho_{w}}{2} \iint \phi_{b} \frac{\partial \phi_{b}}{\partial n} d S,
\end{aligned}
$$

である。実際に側面 $(y= \pm B / 2)$ または端面 $(x=0, L)$ に和ける值を代入し，かつ積分を实行することにより 下記の值が得られる。すなわち

$$
\begin{aligned}
& T_{a a}=\frac{\rho_{w}}{2}\left[W_{a} \cos \omega t\right]^{2} \times L B H \times M_{a a} \\
& T_{b b}=\frac{\rho_{w}}{2}\left[W_{b} \cos \omega t\right]^{2} \times L B H \times M_{b b}
\end{aligned}
$$




$$
\begin{aligned}
& T_{b a}=\frac{\rho_{w}}{2}\left[W_{a} W_{b} \cos ^{2} \omega t\right] \times L B H \times M_{b a} \\
& T_{a b}=\frac{\rho_{w}}{2}\left[W_{a} W_{b} \cos ^{2} \omega t\right] \times L B H \times M_{a b}
\end{aligned}
$$

と打くとき

$$
\begin{aligned}
M_{a a}= & \frac{4}{\pi^{4}} \sum \sum\left\{\frac{1}{\left(i^{2}-1\right)\left(j^{2}-1\right)}\right\}^{2} \varepsilon \frac{\operatorname{coth}\left(n_{i j} B / 2\right)}{n_{i j} B} \\
M_{b b}= & \frac{4}{\pi^{4}} \sum \sum\left\{\frac{1}{\left(i^{2}-1\right)\left(j^{2}-1\right)}\right\}^{2} \varepsilon \frac{\operatorname{coth}\left(N_{i j} L / 2\right)}{N_{i j} L} \\
M_{b a}= & \frac{4}{\pi^{4}}\left(\frac{B}{L}\right) \sum \sum\left\{\frac{-1}{\left(i^{2}-1\right)\left(j^{2}-1\right)^{2}}\right\} \\
& \times \varepsilon \frac{\operatorname{coth}\left(n_{i j} B / 2\right)}{n_{i j} B} \times \frac{1}{\left[1+(i B / L)^{2}+(j B / H)^{2}\right]} \\
M_{a b}= & \frac{4}{\pi^{4}}\left(\frac{L}{B}\right) \sum \sum\left\{\frac{-1}{\left(i^{2}-1\right)\left(j^{2}-1\right)^{2}}\right\} \\
& \times \varepsilon \frac{\operatorname{coth}\left(N_{i j} L / 2\right)}{N_{i j} L} \times \frac{1}{\left[1+(i L / B)^{2}+(j L / H)^{2}\right]}
\end{aligned}
$$

である。以上の計算によつて水の振動の動エネルギー $T_{w}$ の值は

$$
T_{w}=\left[k_{a} A_{a}^{2}+f A_{a} A_{b}+k_{b} A_{b}^{2}\right] C_{p} \omega^{2} \cos ^{2} \omega t
$$

の形に書表わされることがわかる。ここに $W_{a}=\omega A_{a}, W_{b}=\omega A_{b}$ と拈いてある。

\section{4 面振動の場合に対する接水振動の自由振動数略近公式と数値例}

弾性矩形平板が振動しているとき，その歪エネルギーは

$$
U=\frac{1}{2} D \iint\left[\left(\frac{\partial^{2} w}{\partial x^{2}}+\frac{\partial^{2} w}{\partial z^{2}}\right)^{2}-2(1-v)\left\{\frac{\partial^{2} w}{\partial x^{2}} \frac{\partial^{2} w}{\partial z^{2}}-\left(\frac{\partial^{2} w}{\partial x \partial z}\right)^{2}\right] d x d z\right.
$$

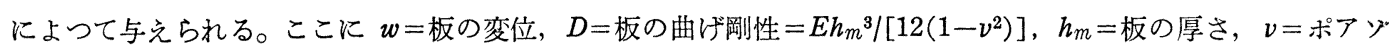
ン比, $E=$ 弾性係数, とする。 2 枚の側面板が (1) の形で, そして 2 枚の端面板が (3)の形で振動していると き, 板の全体の歪みエネルギーは

$$
U=\left[D_{a}\left(m^{2}+s^{2}\right)^{2} \frac{L H}{4} A_{a^{2}}+D_{b}\left(M^{2}+s^{2}\right)^{2} \frac{B H}{4} A_{b}^{2}\right] \sin ^{2} \omega t
$$

また板全体の動エネルギー $T_{m}$ は

$$
T_{m}=\frac{1}{4} \omega^{2}\left[G_{a} A_{a}^{2}+G_{b} A_{b}^{2}\right] \cos ^{2} \omega t
$$

ここに $G_{a}, G_{b}$ はそれぞれの側面板および端面板 1 枚の質量とする。また水槽内部の水の運動のエネルギーは 前述のごとく

$$
T_{w}=\left[k_{a} A_{a}^{2}+f A_{a} A_{b}+k_{b} A_{b}^{2}\right] C_{p} \omega^{2} \cos ^{2} \omega t
$$

の形になる。ゆえに 1 周期 $(t=2 \pi / \omega)$ 間の平均值をとるとさは, 歪みエネルギー $U$ と, 全体の動エネルギー $T_{s}$ とを

$$
\begin{aligned}
& U=C_{U}\left(A_{a^{2}}+\mu A_{b}{ }^{2}\right) \\
& T_{s}=\omega^{2} C_{p}\left(K_{a} A_{a}{ }^{2}+F A_{a} A_{b}+K_{b} A_{b}{ }^{2}\right)
\end{aligned}
$$

の形に書き表わすことができる。もし $U$ と $T s$ とを等しいとおくときには，振動の角周波数 $\omega$ は（簡単のた めに $A_{b} / A_{a}=\lambda$ にと执いて)

$$
\omega^{2}=\frac{C_{U}}{C_{T}} \cdot \frac{1+\mu \lambda^{2}}{K_{a}+F \lambda+K_{b} \lambda^{2}}
$$

比 $\lambda$ の值は未定であるが，1つの自由振動の状態が成り立つために， $\omega$ の值を最小にするような $\lambda$ の值をと. るものとする。そのときの $\lambda$ の值 $\lambda_{m}$ は 2 次方程式

$$
F+2\left(K_{b}-\mu K_{a}\right) \lambda-\mu F \lambda^{2}=0
$$

の根として求められる。 
な特多くの実用問題において，板にスティフナー等が取付けてある場合があるが，この場合には $G, D$ は等価 值をとらねばならない。

上記公式に対する数值例として，前回と同じく $L=5 m, B=H=3 m$ の矩形水槽を考えよう。この場合に対し て上記の公式によつて $M_{a a}, M_{a b}$ 等の值を数值計算すると $M_{a a}=0.16, M_{b b}=0.08, M_{a b}=0.0686, M_{b a}=0.0643$ となる。 $V=45 m^{3}$ であるから，仮性質量（振動の） はとれぞれ $k_{a}=7.20, k_{b}=3.60, f=3.09+2.89=5.98$ と なるから，板自身の質量を考えに入れて $K_{a}=7.50, K_{b}=3.90, F=5.98$ ととることにしよう。板の曲げ剛さ を適当に変えてみることにし，それをパラメータ $\mu$ が変わることで表わす。このとき， $K_{a}: K_{b}$ の割合もいく

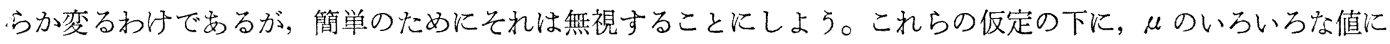

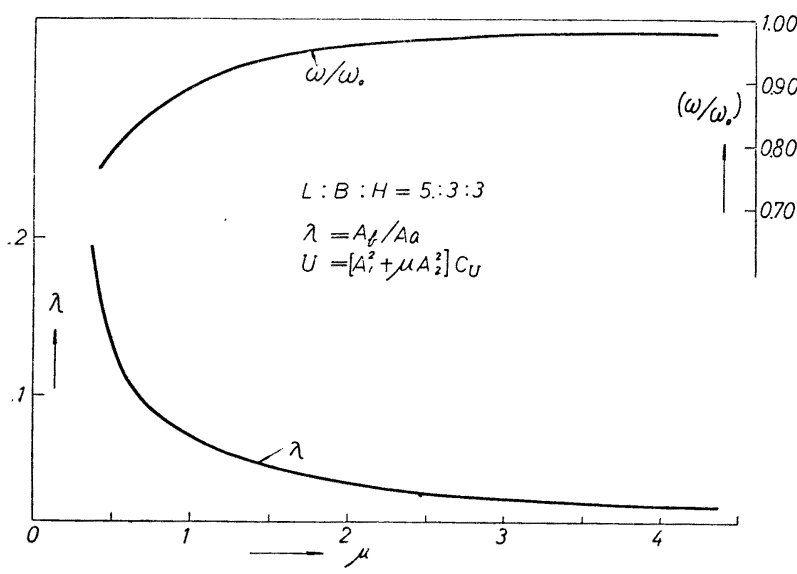

第 2 図 $\left(\omega / \omega_{0}\right)$ と $\lambda$ の值 $(L: B: H=5: 3: 3$ の場合 $)$

対し 2 次方程式 ( 8 ) の根 $\lambda_{m}$ を求め, さらに (7)によりこの $\lambda_{m}$ の值に対する $\omega^{2}$ の值を 計算した。その結果をグラフに示せば第 2 図 のごとくである。図に狳いては横軸に $\mu$ の 值をとり，縦軸には角周波数を比率 $\left(\omega / \omega_{0}\right)$ で 表わしたものと，振幅比 $\lambda$ とがとつてある。 まず 4 枚の矩形板がすべて同じ厚さで, 特汇 スティフナーを取付けてないものとしよう。 このとき

$$
\begin{aligned}
\mu & =\left\{\left(M^{2}+s^{2}\right)^{2} B H\right\} \div\left\{\left(m^{2}+s^{2}\right)^{2} L H\right\} \\
& =1.30
\end{aligned}
$$

であるが，第 2 図によれば，この $\mu$ の值に 対して $\omega / \omega_{0}=0.93, \lambda=0.36$ となる。それ ゆえ，4面全部を考兵に入れた最低の自由振 動数は，2つの側面だけを考えた值の 0.93 倍となり，また 2 つの端面に 2 つの側面の振幅の 0.36 倍の振幅の

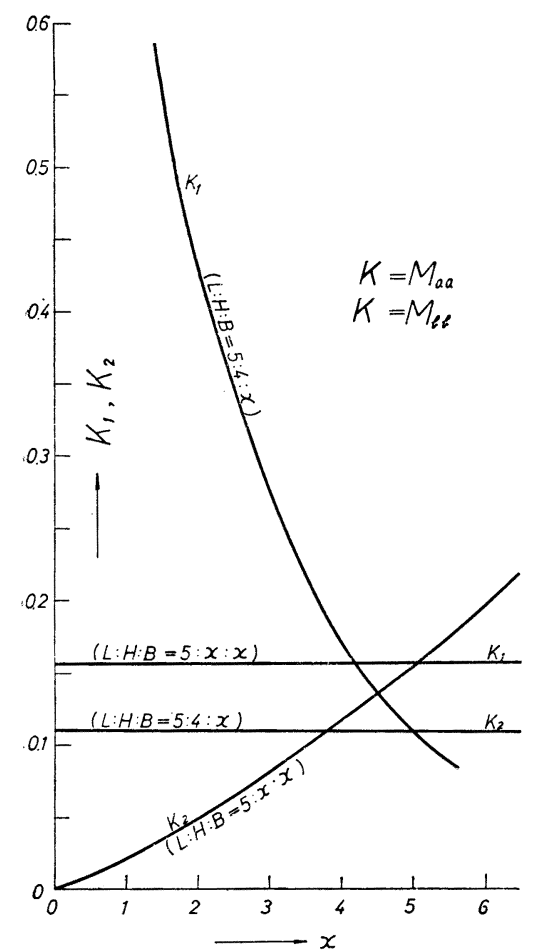

第 3 図種々の比 $L: H: B$ に対する $K_{1}, K_{2}$ の値
振動があることになる。すなわちそのよ5な自由振動 の振動形態があり得ることになる。もしこれ以上に端 面の曲げ剛さが増せば，ほとんど 2 つの側面だけの振 動になるであろう。

最後に, 参考のために, $L: H: B$ の比をいろいる に変えた場合に対する係数 $K_{1}, K_{2}$ 打よび $F$ の值を



第 4 図種々の比 $L: H: B$ に対する $F$ の值 
数値計算によつて求め, 第 3 図拉よ゙第 4 図のグラフに示してめる。

\section{文献}

（1）鬼頭；矩形水槽壁の接水振動について（昭和 34 年 11 月造船協会秋季講演会で講演）

（2）鬼頭；同上（第 2 報）（昭和 35 年 5 月造船協会春季講演会で講演） 